\title{
Dynamic, Nonlinear Feedback Regulation of Slow Pacemaking by A-Type Potassium Current in Ventral Tegmental Area Neurons
}

\author{
Zayd M. Khaliq and Bruce P. Bean \\ Department of Neurobiology, Harvard Medical School, Boston, Massachusetts 02115
}

We analyzed ionic currents that regulate pacemaking in dopaminergic neurons of the mouse ventral tegmental area by comparing voltage trajectories during spontaneous firing with ramp-evoked currents in voltage clamp. Most recordings were made in brain slice, with key experiments repeated using acutely dissociated neurons, which gave identical results. During spontaneous firing, net ionic current flowing between spikes was calculated from the time derivative of voltage multiplied by cell capacitance, signal-averaged over many firing cycles to enhance resolution. Net inward interspike current had a distinctive nonmonotonic shape, reaching a minimum (generally $<1$ $\mathrm{pA}$ ) between -60 and $-55 \mathrm{mV}$. Under voltage clamp, ramps over subthreshold voltages elicited a time- and voltage-dependent outward current that peaked near $-55 \mathrm{mV}$. This current was undetectable with $5 \mathrm{mV} / \mathrm{s}$ ramps and increased steeply with depolarization rate over the range $(10-50 \mathrm{mV} / \mathrm{s})$ typical of natural pacemaking. Ramp-evoked subthreshold current was resistant to $\alpha$-dendrotoxin, paxilline, apamin, and tetraethylammonium but sensitive to 4-aminopyridine and $0.5 \mathrm{~mm} \mathrm{Ba}^{2+}$, consistent with A-type potassium current $\left(I_{\mathrm{A}}\right)$. Same-cell comparison of currents elicited by various ramp speeds with natural spontaneous depolarization showed how the steep dependence of $I_{\mathrm{A}}$ on depolarization rate results in small net inward currents during pacemaking. These results reveal a mechanism in which subthreshold $I_{\mathrm{A}}$ is near zero at steady state, but is engaged at depolarization rates $>10 \mathrm{mV} / \mathrm{s}$ to act as a powerful, supralinear feedback element. This feedback mechanism explains how net ionic current can be constrained to $<1-2 \mathrm{pA}$ but reliably inward, thus enabling slow, regular firing.

Key words: $I_{\mathrm{A}} ; I_{\mathrm{K}} ; 4$-aminopyridine; spontaneous firing; A-type; dopaminergic neurons; VTA

\section{Introduction}

Many types of central neurons fire action potentials in a rhythmic manner in the absence of synaptic input. Such pacemaking activity occurs with a wide range of speeds in different types of neurons. Dopaminergic neurons of the ventral tegmental area (VTA) have intrinsic membrane properties that produce spontaneous firing at relatively low frequencies, typically $0.5-5 \mathrm{~Hz}$ (Johnson and North, 1992; Cameron et al., 1997; Neuhoff et al., 2002; Korotkova et al., 2003; Koyama et al., 2005; Margolis et al., 2006). The ionic mechanisms that enable stable firing at low frequencies in VTA and other pacemaking neurons in the mammalian brain are not well understood. In general, the ability to fire repetitively at low frequencies has been associated with the voltagedependent potassium current known as A-type current $\left(I_{\mathrm{A}}\right)$, which activates and inactivates at subthreshold voltages (Connor and Stevens, 1971a,b; Rudy, 1988; Jerng et al., 2004). VTA neurons express prominent $I_{\mathrm{A}}$ (Koyama and Appel, 2006b), and in

\footnotetext{
Received May 17, 2008; revised Sept. 10, 2008; accepted Sept. 11, 2008.

This work was supported by National Institutes of Health (NIH) Grant NS36855. Z.M.K. was supported by NIH Grant T32-NS007484. We thank Brett Carter, Alex Jackson, and Michelino Puopolo for help, advice, and comments on this manuscript.

Correspondence should be addressed to Zayd M. Khaliq, Department of Neurobiology, Harvard Medical School, 220 Longwood Avenue, Boston, MA 02115. E-mail: zayd khaliq@hms.harvard.edu. DOI:10.1523/JNEUROSCI.2237-08.2008

Copyright $\odot 2008$ Society for Neuroscience $\quad$ 0270-6474/08/2810905-13\$15.00/0
}

dopaminergic neurons of the substantia nigra, speed of pacemaking was found to be inversely correlated with $I_{\mathrm{A}}$ magnitude (Liss et al., 2001; Hahn et al., 2003, 2006). Thus, it is reasonable to suppose that $I_{\mathrm{A}}$ may play an important role in regulating firing of VTA neurons. However, the mechanism by which $I_{\mathrm{A}}$ influences firing rate (i.e., the time dependence and magnitude of $I_{\mathrm{A}}$ flowing between spikes) in VTA or other neurons is unclear and has been approached mainly by computer modeling (Connor and Stevens, 1971b; Gerber and Jakobsson, 1993; Rush and Rinzel, 1995; Xiao et al., 2004), with a lack of experimental data attempting to directly quantify flow of $I_{\mathrm{A}}$ during natural pacemaking.

In general, determining the role of individual conductances in controlling pacemaking is challenging, partly because of the small size of currents involved. Often the role of specific conductances in pacemaking is assessed by using pharmacological blockers in current-clamp recordings, but such results can be hard to interpret because changing one current generally causes indirect changes in other currents as a result of the altered voltage trajectory. Another approach is computer modeling, but this requires accurate kinetic models for multiple currents, which is especially difficult to accomplish for the small currents near threshold. We analyzed the conductances regulating pacemaking activity in dopaminergic neurons of the VTA using a different approach, taking advantage of the regularity of firing to signal-average interspike voltage trajectories, from which we could quantify the 
magnitude and voltage dependence of the net ionic current underlying pacemaking. Complementary experiments in voltage clamp, using voltage ramps at speeds similar to natural voltage trajectories, then distinguished individual components of subthreshold current based on time dependence, voltage dependence, and pharmacology. We found a dynamic component of outward current that activates at voltages as negative as $-70 \mathrm{mV}$ and has a complex time dependence and voltage dependence. This current, which could be identified as $I_{\mathrm{A}}$, was unmeasurably small with very slow ramps $(5 \mathrm{mV} / \mathrm{s})$ but increased very steeply with ramp speed, making it a powerful, highly nonlinear negative feedback element to control pacemaking frequency.

\section{Materials and Methods}

Coronal brain slices containing the ventral tegmental area were prepared from postnatal day 14 (P14)-P30 transgenic mice in which enhanced green fluorescent protein (EGFP) is driven by the tyrosine hydroxylase (TH) promoter [the $\mathrm{Tg}(\mathrm{TH}-\mathrm{EGFP}) 1$ Gsat Gene Expression Nervous System Atlas (GENSAT) line, obtained from the National Institutes of Health Mutant Mouse Regional Resource Center]. Animals were anesthetized with isoflurane and swiftly decapitated. Their brains were quickly removed and placed into an ice-cold sucrose slicing solution containing (in mM) $87 \mathrm{NaCl}, 25 \mathrm{NaHCO}_{3}, 1.25 \mathrm{NaH}_{2} \mathrm{PO}_{4}, 2.5 \mathrm{KCl}, 7.5$ $\mathrm{MgCl}_{2}, 75$ sucrose, and 25 glucose, bubbled with $95 / 5 \% \mathrm{O}_{2} / \mathrm{CO}_{2}$. Slices were cut using a vibratome (DSK model DTK-1000; Dosaka) and incubated for $1 \mathrm{~h}$ at $34^{\circ} \mathrm{C}$, first for $30 \mathrm{~min}$ in slicing solution and then for 30 min in artificial CSF consisting of (in mM) $125 \mathrm{NaCl}, 25 \mathrm{NaHCO}_{3}, 1.25$ $\mathrm{NaH}_{2} \mathrm{PO}_{4}, 3.5 \mathrm{KCl}, 1 \mathrm{MgCl}_{2}, 2 \mathrm{CaCl}_{2}$, and 10 glucose, bubbled with $95 / 5 \% \mathrm{O}_{2} / \mathrm{CO}_{2}$.

Slices were placed into a heated recording chamber $\left(34 \pm 1^{\circ} \mathrm{C}\right)$ and continuously perfused at a rate of $3 \mathrm{ml} / \mathrm{min}$ with a HEPES-buffered Tyrode's solution containing (in $\mathrm{mm}$ ) $151 \mathrm{NaCl}, 3.5 \mathrm{KCl}, 2 \mathrm{CaCl}_{2}, 1$ $\mathrm{MgCl}_{2}, 10$ glucose, and 10 HEPES, pH adjusted to 7.35 with $\mathrm{NaOH}$. All recordings were made in the presence of blockers of fast synaptic transmission: $20 \mu \mathrm{M}$ 6-cyano-7-nitroquinoxaline-2,3-dione (CNQX), $50 \mu \mathrm{M}$ D,L-amino-5-phosphopentanoic acid (APV), and $100 \mu \mathrm{M}$ picrotoxin. Dopaminergic neurons were identified as green fluorescent protein (GFP)-positive neurons using epifluorescence and a CCD camera (MTI) on a Nikon microscope (E600FN). Whole-cell current-clamp or voltageclamp recordings were made with a Multiclamp 700B amplifier (Molecular Devices) using borosilicate patch electrodes (1-3 M $\Omega$ ) wrapped with Parafilm to reduce pipette capacitance. Electrodes were filled with internal solution containing (in mM) $122 \mathrm{~K}$-methanesulfonate, $9 \mathrm{NaCl}, 1.8$ $\mathrm{MgCl}_{2}, 4 \mathrm{Mg}$-ATP, $0.3 \mathrm{Na}$-GTP, 14 phosphocreatine, 0.45 EGTA, 0.1 $\mathrm{CaCl}_{2}$, and 10 HEPES, $\mathrm{pH}$ adjusted to 7.35 with $\mathrm{KOH}$.

Reported voltages are corrected for a liquid junction potential of -8 $\mathrm{mV}$ between the internal solution and the chamber solution, measured using a flowing $3 \mathrm{M} \mathrm{KCl} \mathrm{electrode} \mathrm{as} \mathrm{described} \mathrm{by} \mathrm{Neher} \mathrm{(1992).} \mathrm{Pipette}$ series resistance (typically $4-8 \mathrm{M} \Omega$ ) was compensated by $70-85 \%$ during voltage-clamp experiments and was checked frequently throughout the experiment; data were not used if series resistance changed by $>15 \%$. Current and voltage signals were filtered at $10 \mathrm{kHz}$ and sampled at $20 \mu \mathrm{s}$ using a Digidata 1322A data-acquisition interface (Molecular Devices) and pClamp 9 software (Molecular Devices).

After obtaining the seal and whole-cell configuration, the cells were perfused with HEPES-based extracellular solutions applied locally in the vicinity of the cell using a $700-\mu \mathrm{m}$-diameter quartz tube. Solutions were exchanged by switching between various solutions supplying this perfusion tube, which was heated by contact $(\sim 9 \mathrm{~cm})$ with a heated aluminum plate, controlled by a TC-344 (Warner Instruments) temperature controller. This system allowed relatively rapid solution changes with maintenance of a well-defined temperature. All experiments were done at a temperature of $34 \pm 1^{\circ} \mathrm{C}$.

During both current-clamp and voltage-clamp experiments, stable baseline values were obtained for $2-5 \mathrm{~min}$ before drug application. Experiments were aborted if significant drift was observed in baseline spike frequency or current amplitude. When solutions were prepared containing 4-aminopyridine (4-AP), $\mathrm{pH}$ was readjusted to 7.35 using $\mathrm{HCl}$. In some experiments with $200 \mathrm{~nm} \alpha$-dendrotoxin, $1 \mathrm{mg} / \mathrm{ml}$ bovine serum albumin was added to reduce any binding of the toxin to the perfusion tube. Results with or without bovine serum albumin were indistinguishable.

Data analysis was done using pClamp9 and IgorPro version 4.06 (Wavemetrics), using DataAccess (Bruxton) to read pClamp files into Igor. In voltage-clamp experiments, capacitative transients were reduced by using electronic capacitance compensation in the amplifier circuit. For voltage protocols using step depolarizations, current records were corrected for small leak and remaining capacitative currents, using 5 or $10 \mathrm{mV}$ hyperpolarizing or depolarizing steps (usually from -78 to -83 $\mathrm{mV}$ ) to define linear capacitance and leak currents and then subtracting appropriately scaled currents for larger steps of voltage. For currents recorded using ramp voltage commands, current was plotted as a function of voltage and leak current was defined by a linear fit to current in the range from -78 to $-70 \mathrm{mV}$, as shown in Figure $3 B$, and then subtracted as shown in Figure $3 C$. In cells in which nonlinear outward current began to activate at or below $-70 \mathrm{mV}$, the fit for leak current was made over a slightly more negative range. In a few experiments, as noted in the Figure legends, $2 \mathrm{~mm} \mathrm{Cs}^{+}$was added to the external solution to block small currents from $I_{\mathrm{h}}$ that were sometimes present negative to $-80 \mathrm{mV}$. This enabled more precise leak correction because background currents were more reliably linear over a wider voltage range. However, $\mathrm{Cs}^{+}$was not used in most experiments because $I_{\mathrm{h}}$ was generally negligible positive to $-80 \mathrm{mV}$. There was no apparent effect of $\mathrm{Cs}^{+}$on the voltage dependence or magnitude of either step-evoked or ramp-evoked $I_{\mathrm{A}}$, and statistics for current sizes used lumped values from experiments with or without $2 \mathrm{mM}$ $\mathrm{Cs}^{+}$.

Interspike ionic current was calculated from $-C \times d V / d t$, where $C$ is the cell capacitance and $d V / d t$ is the time derivative of the voltage during spontaneous firing. To increase resolution, voltage signals were signalaveraged over multiple cycles of firing (typically 40-100), aligning individual cycles at the spike peaks. The calculated ionic current was plotted as a function of voltage as in Figure $2 C$, and to further decrease noise, $-C \times d V / d t$ was averaged over bins corresponding to a 0.05 or $0.1 \mathrm{mV}$ change in voltage.

Cell capacitance was measured by integrating capacitative transients from 5 or $10 \mathrm{mV}$ steps given in the range between -78 and $-68 \mathrm{mV}$. Capacitance values were obtained either by direct integration of uncompensated capacitative transients or from transients recorded with analog capacity compensation enabled on the amplifier, in which case the value of capacity used in the amplifier circuit to cancel the dominant fast component was summed with the integral of the remaining uncompensated slower components. The two procedures gave very similar results in cells in which both were compared.

For studies on acutely dissociated neurons, the ventral tegmental area was dissected from brain slices cut from P15-P18 Tg(TH-EGFP)1Gsat mice. Tissue was treated with $3 \mathrm{mg} / \mathrm{ml}$ protease XXIII (Sigma) for $10 \mathrm{~min}$ at $23^{\circ} \mathrm{C}$ in a solution consisting of (in $\mathrm{mM}$ ) $82 \mathrm{Na}_{2} \mathrm{SO}_{4}, 30 \mathrm{~K}_{2} \mathrm{SO}_{4}, 5$ $\mathrm{MgCl}_{2}, 10 \mathrm{HEPES}$, and 10 glucose. After brief treatment with trypsin inhibitor $(1 \mathrm{mg} / \mathrm{ml})$, the tissue was stored in the same solution. Cells were isolated by gentle trituration, and dopaminergic VTA neurons were identified by EGFP fluorescence. Both current-clamp and voltage-clamp recordings were made at $34^{\circ} \mathrm{C}$ using the same internal and external solutions (except that synaptic blockers were omitted) and the same voltage protocols used for the slice recordings.

Statistics are given as mean $\pm \mathrm{SD}$, and statistical significance tests were done using nonparametric tests (Wilcoxon or Mann-Whitney).

\section{Results}

We recorded from dopaminergic neurons in the VTA in brain slices. To unambiguously identify dopaminergic neurons, all experiments were done using slices prepared from transgenic mice in which expression of EGFP is driven by the tyrosine hydroxylase promoter, generated as part of the GENSAT bacterial artificial chromosome project (Gong et al., 2003). We recorded from EGFP-expressing neurons located in the medial half of the VTA, away from the border of the VTA with the substantia nigra. Elec- 
trophysiological properties of the EGFP-expressing neurons were consistent with those reported previously for dopaminergic neurons in the VTA of wild-type mice (Ford et al., 2006), and we saw no differences in any properties or the health of cells from transgenic animals compared with our own recordings from presumptive dopaminergic neurons in the VTA of wild-type mice.

To focus on intrinsic membrane properties, all recordings were made in the presence of synaptic blockers (50 $\mu \mathrm{M}$ D-APV, 20 $\mu \mathrm{M}$ CNQX, and $100 \mu \mathrm{M}$ picrotoxin). It has previously been described that there are subsets of principal dopaminergic neurons within the VTA with somewhat different electrophysiological properties (Wolfart et al., 2001; Neuhoff et al., 2002; Koyama et al., 2005; Ford et al., 2006; Lammel et al., 2008), which can be correlated to at least some extent with the brain regions to which they project (Ford et al., 2006; Lammel et al., 2008). Consistent with previous results using dissociated neurons (Koyama et al., 2005), we found that individual VTA neurons could show either regular or irregular spontaneous firing, even in the absence of fast synaptic input. Because our goal was to relate details of the voltage trajectory during pacemaking to currents in voltage clamp, we focused on neurons that showed regular firing, for which the voltage trajectory can be well defined by signal-averaging. These constituted the majority $(\sim 75 \%)$ of all the neurons from which we recorded.

Figure $1 A$ shows an example of spontaneous firing in a regular firing VTA neuron. The neuron fired at $1.3 \mathrm{~Hz}$, and firing was highly rhythmic (Fig. $1 A, B$ ), with a coefficient of variation of $11 \%$ for the duration of interspike intervals. The firing rate of individual neurons varied from 0.5 to $6 \mathrm{~Hz}$, with an average frequency of $2.1 \pm 1.1 \mathrm{~Hz}$ (mean $\pm \mathrm{SD} ; n=50$ ) (Fig. $1 C$ ). The average coefficient of variation for interspike intervals was $13 \pm$ $7 \%$ (mean $\pm \mathrm{SD} ; n=50$ cells). Action potentials had a width at half-maximum amplitude of $1.44 \pm 0.31 \mathrm{~ms}(n=50)$, in excellent agreement with previous recordings of principal dopaminergic neurons in the VTA at a similar temperature (Ford et al., 2006).

Figure $1 D$ shows at higher resolution the voltage trajectory during the interspike interval of spontaneous firing in a typical VTA dopaminergic neuron. In this cell, which fired at $1.3 \mathrm{~Hz}$, the most negative voltage reached after a spike was $-67 \mathrm{mV}$, and the rate of spontaneous depolarization in the middle of the region between spikes was $17 \mathrm{mV} / \mathrm{s}$. The rate of spontaneous depolarization during the interspike interval varied considerably from neuron to neuron, over a range from 5 to $100 \mathrm{mV} / \mathrm{s}$, with an average rate of $29 \pm 22 \mathrm{mV} / \mathrm{s}$ (measured in the middle $40 \%$ of the interspike interval; $n=49$ ) (Fig. $1 E$ ).

In a neuron firing spontaneously without current injection, the spontaneous depolarization during the interspike interval results from flow of net inward ionic current, which depolarizes the voltage across the membrane capacitance. In the formalism introduced by Hodgkin et al. (1952), total membrane current can be divided into components of ionic current and capacitative current. In the absence of exogenously injected current, total membrane current is zero, so that net ionic current is equal and opposite to the capacitative current, $C \times d V / d t$. Thus, by measuring the rate of interspike depolarization $(d V / d t)$ and the membrane capacitance $(C)$, it is possible to calculate the net ionic current flowing through the neuronal membrane during the spontaneous depolarization as $-C \times d V / d t$. This simple calculation offers a powerful tool for quantifying the flow of ionic current during the interspike interval. During any individual interspike interval, the voltage trajectory is not completely smooth, and the calculated ionic current is very noisy at the picoampere
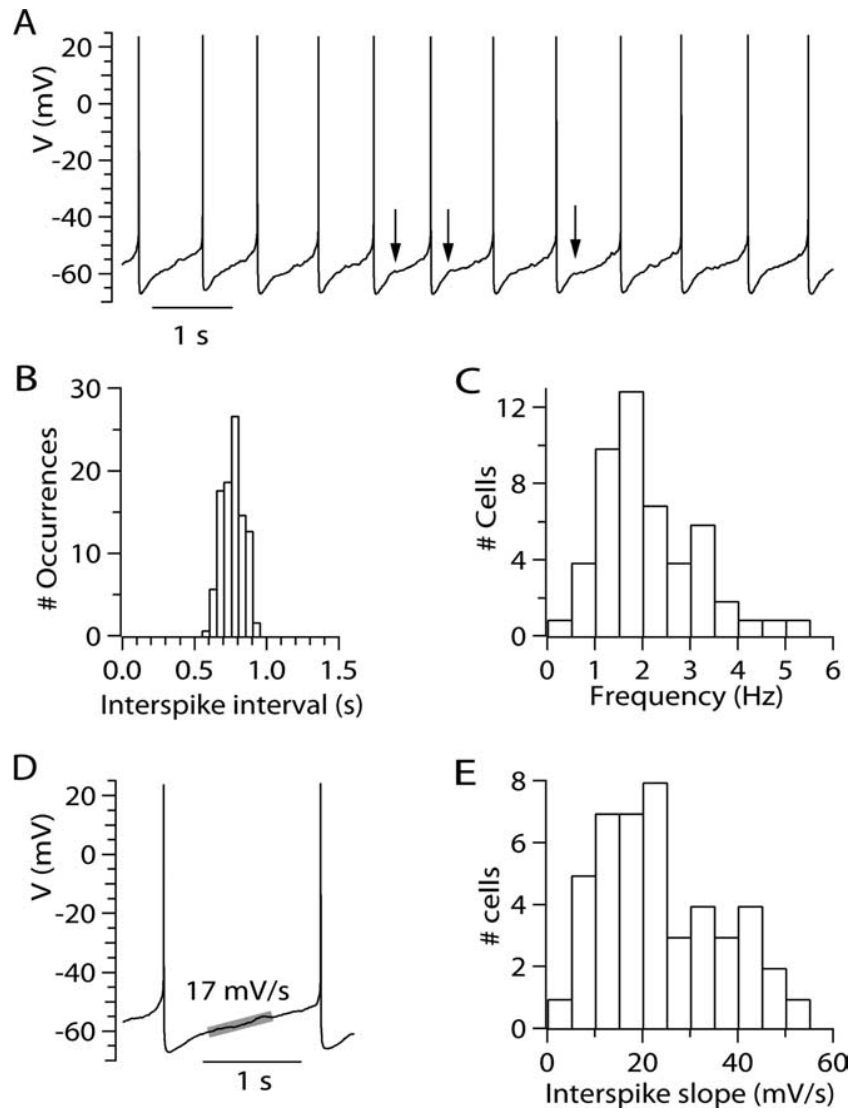

Figure 1. Characteristics of pacemaking in VTA dopaminergic neurons. $A$, Spontaneous firing in a VTA dopaminergic neuron. Arrows indicate inflections in voltage trajectory consistent with voltage-dependent activation of outward current. $\boldsymbol{B}$, Histogram of interspike intervals (over a 77 s period) for the cell whose firing is shown in $\boldsymbol{A}$. C, Histogram of firing frequency for 50 VTA neurons. $\boldsymbol{D}$, Trajectory of voltage during the interspike interval. Broad gray line shows fitted slope to the middle region of the interspike interval (fitted to the middle $40 \%$ of the interspike interval) for the first interspike interval in the record shown in $\boldsymbol{A}$. $\boldsymbol{E}$, Histogram of interspike slopes for 49 cells. The value for each cell was determined as the slope over the middle $40 \%$ of the interspike interval, for each cell averaged over 40-150 individual interspike intervals.

scale. However, if the firing is sufficiently regular, it is possible to signal-average the voltage trajectory over many firing cycles to obtain better precision. Figure 2 illustrates the procedure for calculation of net ionic current during the interspike interval. From a record of spontaneous firing over $77 \mathrm{~s}$ (100 spikes), the average voltage trajectory between spikes was calculated by aligning individual spikes at their peaks and signal-averaging the voltage trajectories before and after the spike (Fig. $2 \mathrm{~A}$ ). Although there was some variability in each voltage trajectory, the SD of the voltage at each time relative to the spike (calculated over the population) was $<1 \mathrm{mV}$ for times less than half of the average interspike interval on either side of the spike. (This result was typical; in collected results for firing in 40 neurons, the SD of the voltage, measured at each end of a complete cycle of firing as in Fig. $2 \mathrm{~A}$, was on average $1.05 \pm 0.36 \mathrm{mV}$.) The relatively small variability makes it seem reasonable to calculate an average voltage trajectory during a complete firing cycle, which we did by linking together signal-averaged hemicycles, one preceding and one succeeding the spike peak, each ending at the same voltage (limits are indicated in Fig. $2 A$, red line with arrows). Figure $2 B$ shows the signal-averaged voltage trajectory for the complete cycle calculated in this way. From this, we calculated net ionic current at each time point from $-C \times d V / d t$ of the signal-averaged voltage 
(Fig. $2 \mathrm{~B}$, bottom trace). Although this calculation would be extremely noisy for any single cycle, the calculation from the signal-averaged voltage trajectory was smooth enough to give picoampere-level resolution. The calculation shows that the net inward current flowing during the interspike interval to drive pacemaking is remarkably small, amounting to $<1.5 \mathrm{pA}$ for most of the interspike interval. A large proportion of the total interspike interval is spent traversing the region of voltage from -60 to $-55 \mathrm{mV}$, the part of the interspike interval where net inward current is smallest. Of the total interspike interval of $751 \mathrm{~ms}$ (spike peak to spike peak), 372 ms was spent depolarizing the membrane from -60 to $-55 \mathrm{mV}$ (Fig. $2 B$, arrows).

A useful view of ionic current flow during the interspike interval is provided by plotting ionic current (calculated from $-C \times d V / d t$ ) as a function of voltage (Fig. $2 C)$. In such plots, there was reliably a distinct concavity in the relationship between ionic current and membrane voltage, such that inward current reached a minimum between -60 and $-55 \mathrm{mV}$. On average, the smallest inward current occurred at $-58 \pm 4 \mathrm{mV}(n=40)$ and varied from $0.1-6 \mathrm{pA}$ in individual cells, with an average of $0.9 \pm 1.0 \mathrm{pA}(n=40)($ Fig. $2 D)$.

To determine the types of ionic currents that contribute to net ionic current flow at subthreshold voltages, we recorded in voltage-clamp mode and elicited currents by voltage ramps delivered at rates similar to those typical of the spontaneous depolarization between spikes during pacemaking (Fig. 3). Figure $3 A$ shows the total membrane current evoked by a depolarizing voltage ramp with a speed of 30 $\mathrm{mV} / \mathrm{s}$ (chosen to be similar to a typical rate of spontaneous depolarization during the interspike interval). The ramp-evoked current was linear in the range from -78 to $-70 \mathrm{mV}$, with a slope corresponding to an input resistance of $1.2 \mathrm{G} \Omega$ (on average, $0.95 \pm 0.29 \mathrm{G} \Omega ; n=31)$. Positive to $-70 \mathrm{mV}$, there were nonlinear components of the current-voltage relationship. These nonlinear components could be most clearly defined when the current-voltage relationship was corrected for the current corresponding to the linear background conductance (Fig. 3B). There were two components of nonlinear, voltage-dependent current evident (Fig. 3C): a low-threshold outward component of current that first activated between -70 and $-65 \mathrm{mV}$ and reached a peak near $-55 \mathrm{mV}$, followed by an inward component that reached a peak near -40 $\mathrm{mV}$. In collected results from 25 neurons, the low-threshold outward component of current evoked by ramps at $30 \mathrm{mV} / \mathrm{s}$ reached a maximum of $33 \pm 15 \mathrm{pA}$ at a voltage of $-55 \pm 2 \mathrm{mV}$. The voltage of peak outward current is very similar to the voltage of the minimum inward current value of the interspike $-C \times d V / d t$ concavity (Fig. $2 C)$. The comparison suggests that the concavity results from active engagement of a voltage-dependent outward current.
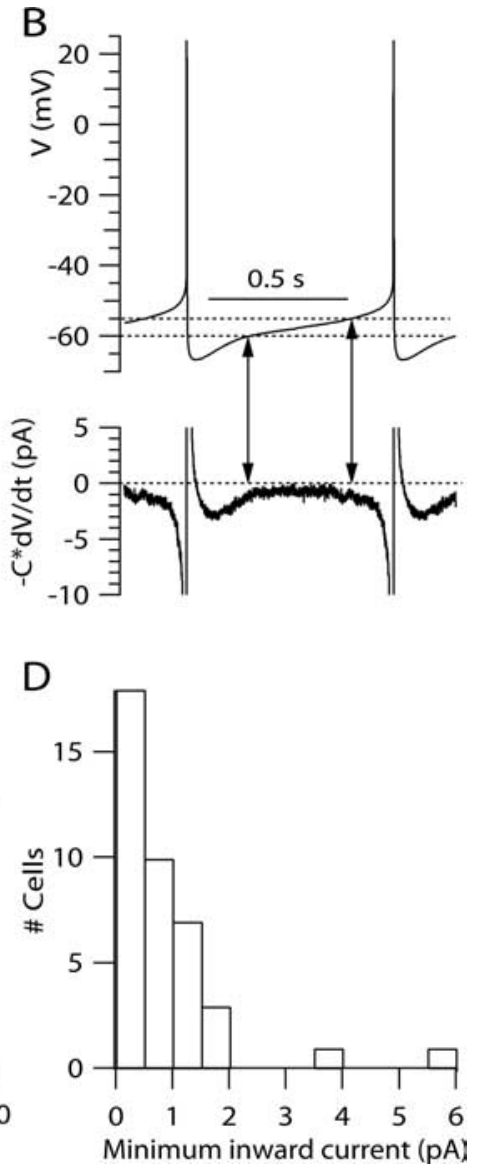

Figure 2. Analysis of net ionic current during the interspike interval from averaged voltage trajectories. $\boldsymbol{A}$, One hundred successive spikes (gray traces) from a segment of spontaneous firing were aligned at their peaks and signal-averaged over a period ( \pm 950 ms from each peak) long enough to include preceding and succeeding spikes for each spike. Black trace shows the average. (same cell as Fig. 1). $\boldsymbol{B}$, Top trace, Averaged voltage trajectory during the interspike interval defined from the signal-averaged

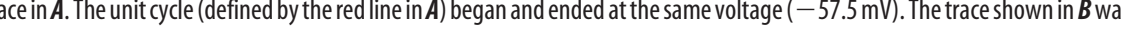
signal-avaged voltage traject. The trace was digitally fiter corner frequency of $0.5 \mathrm{kHz}$. Cell capacitance was $61 \mathrm{pF}$. Vertical lines with arrows indicate times at which the interspike voltage crosses $-60 \mathrm{mV}$ and $-55 \mathrm{mV}$ levels. $C$, Net ionic current calculated from $-C \times d V / d t$ plotted as a function of voltage. Smooth reached (solid red circle). Lines with arrows indicate -60 and $-55 \mathrm{mV}$. D, Histogram of minimum inward current during the interspike interval (measured as in $\mathbf{C}$ ) for 40 neurons.

Application of 300 nM TTX blocked the inward component of ramp-evoked current, suggesting that this component represents steady-state or persistent Na current. In the presence of TTX (Fig. $3 C$, gray trace), it was clear that the ramp-evoked outward current had two distinct phases: a low-threshold component that reached a plateau near $-50 \mathrm{mV}$ and a larger component that began to activate steeply near $-45 \mathrm{mV}$.

To test whether the low-threshold component of outward current during $30 \mathrm{mV} / \mathrm{s}$ ramps is a true steady-state current, we tested very slow voltage ramps of $5 \mathrm{mV} / \mathrm{s}$ (Fig. 3D). We found that although the TTX-sensitive inward component was still present at slow ramp speeds, the low-threshold component of outward current was not. Instead, the total membrane current from -80 to approximately $-55 \mathrm{mV}$ was consistently either linear (most cells, as for that shown in Fig. 3) or, in a few cells, slightly inward. These results show that the low-threshold outward current is not 
A

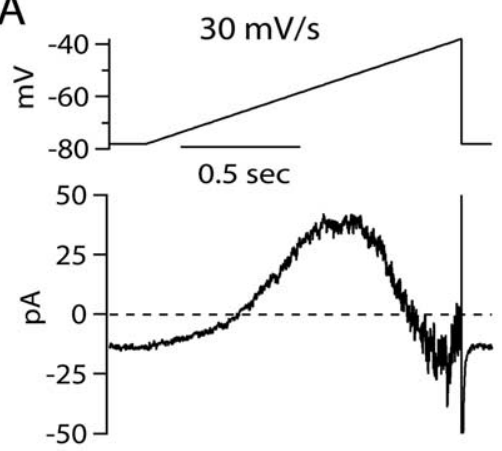

C

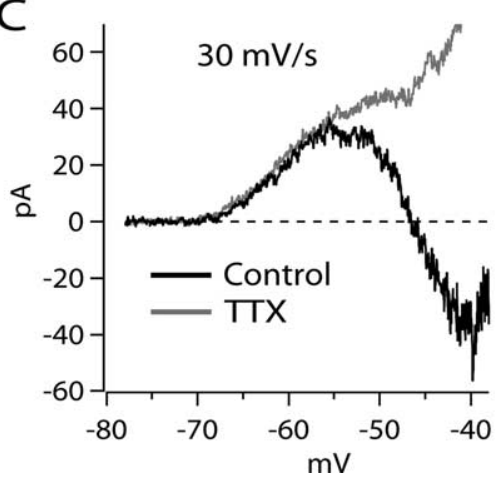

B

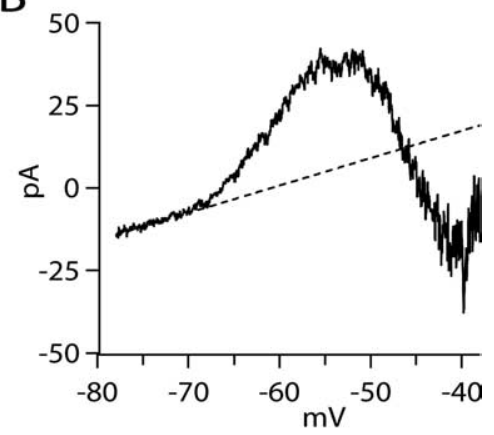

D

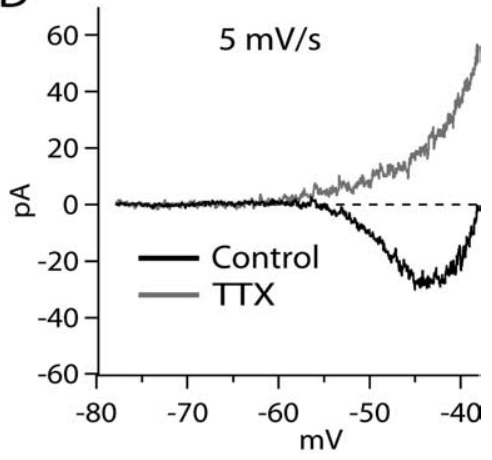

Figure 3. Subthreshold currents evoked by slow voltage ramps. $\boldsymbol{A}$, Raw current evoked by a $30 \mathrm{mV} / \mathrm{s}$ voltage ramp from -78 to $-38 \mathrm{mV}$. $\boldsymbol{B}$, Ramp-evoked current from $\boldsymbol{A}$, plotted as a function of voltage. A fit-to-linear leak current between -78 and -70 $\mathrm{mV}$ is shown as a dotted line, extrapolated assuming ohmic behavior. C, Black trace, Ramp-evoked current corrected for linear leak current as determined in $\boldsymbol{B}$. Gray trace, Same as the black trace, but after application of $300 \mathrm{~nm}$ TTX. $\boldsymbol{D}$, Current-voltage relationship for current evoked by $5 \mathrm{mV} / \mathrm{s}$ ramp before and after application of $300 \mathrm{~nm}$ TTX (same cell as in $\boldsymbol{A}-\boldsymbol{C}$ ).

paminergic neurons responds dynamically to changes in ramp speed by increasing in a highly supralinear manner.

We next tested the pharmacology of the subthreshold outward current to determine what channel types contribute to it. Some voltage-activated potassium channels in the Kv1-family can activate at subthreshold voltages and strongly regulate firing. Such subthreshold Kv1-mediated current has been described in medium spiny striatal neurons (Shen et al., 2004), cerebellar Purkinje neurons (Khavandgar et al., 2005), hippocampal pyramidal neurons (Golding et al., 1999; Metz et al., 2007), and neocortical pyramidal neurons (Guan et al., 2007; Kole et al., 2007). In all of these cases, the current is blocked by $\alpha$-dendrotoxin, which inhibits Kv1.1, Kv1.2, and Kv1.6-containing channels (Coetzee et al., 1999). We therefore tested $200 \mathrm{nM} \alpha$-dendrotoxin on the rampevoked current. Dendrotoxin had little or no effect on the low-threshold component of ramp-evoked current (Fig. 5A). In collected results, current evoked by $60 \mathrm{mV} / \mathrm{s}$ ramps measured at $-50 \mathrm{mV}$ was reduced by $5 \pm 13 \%$ by $200 \mathrm{nM} \alpha$-dendrotoxin $(n=10)$. However, the effectiveness of the toxin was demonstrated by partial inhibition of the second phase of outward current flowing at voltages positive to -40 $\mathrm{mV}$ (Fig. $5 A$, inset) (outward current mea-

a true steady-state current but rather an active current that is sensitive to the speed of depolarization. If there is any true steadystate nonlinear outward current at voltages negative to $-55 \mathrm{mV}$, it is below the resolution possible in these experiments (limited by noise within traces, trace-to-trace variability and in some cells, a small voltage-dependent inward current). Based on the resolution in traces obtained with slow ramps of $5 \mathrm{mV} / \mathrm{s}$ in this and other cells, we can put an upper limit of $\sim 2 \mathrm{pA}$ on any true steady-state voltage-dependent outward current in this voltage range.

We next characterized the dependence of the low-threshold component of outward component on ramp speed over a range of speeds from 5 to $70 \mathrm{mV} / \mathrm{s}$ (Fig. 4). These experiments were done in the presence of $300 \mathrm{nM}$ TTX to better isolate the component of nonlinear outward current. Ramps at $5 \mathrm{mV} / \mathrm{s}$ did not evoke clear nonlinear outward current below $-55 \mathrm{mV}$. In most cells, the current evoked by ramps at $10 \mathrm{mV} / \mathrm{s}$ was barely detectably different from that evoked by $5 \mathrm{mV} / \mathrm{s}$ ramps, but $20 \mathrm{mV} / \mathrm{s}$ ramps always evoked clear nonlinear outward current. Lowthreshold ramp-evoked current increased steeply with ramp speeds from 20 to $70 \mathrm{mV} / \mathrm{s}$, amounting to an average of $13 \pm 9 \mathrm{pA}$ at $20 \mathrm{mV} / \mathrm{s}, 29 \pm 20 \mathrm{pA}$ at $30 \mathrm{mV} / \mathrm{s}$, and $81 \pm 46 \mathrm{pA}$ at $60 \mathrm{mV} / \mathrm{s}$ (measured at $-50 \mathrm{mV} ; n=39$ ). The highly nonlinear dependence of the low-threshold outward current on ramp speed was especially clear when the current was plotted as a function of ramp speed for each neuron. In the data from the cell shown in Figure 4, the relationship between 5 and $40 \mathrm{mV} / \mathrm{s}$ could be fit well with a power function with an exponent of 2.1 (Fig. $4 B$ ). In collected results from 31 neurons, the average exponent value was $2.6 \pm 0.8$. Thus, the low-threshold outward current in VTA do- sured at $-28 \mathrm{mV}$ was reduced by $19 \pm 9 \% ; n=5)$.

Another possibility is that the outward current represents calcium-activated potassium current. However, coapplying 300 nM apamin, a blocker of small conductance (SK) calciumactivated potassium currents, and $3 \mu \mathrm{M}$ paxilline, a blocker of large conductance (BK) calcium-activated potassium currents, had very little effect on the subthreshold component of outward current (Fig. 5B), while substantially inhibiting higher-threshold current. In collected results, the combination of $300 \mathrm{~nm}$ apamin and $3 \mu \mathrm{M}$ paxilline reduced ramp-evoked $(60 \mathrm{mV} / \mathrm{s})$ outward current measured at $-50 \mathrm{mV}$ by $7 \pm 7 \%(n=5)$ and reduced outward current measured at $-28 \mathrm{mV}$ by $40 \pm 23 \%(n=10)$. The results show that, although there is substantial calciumactivated potassium current present in the neurons, it contributes little or no current at subthreshold voltages during the voltage ramps.

We also tested the effect of $10 \mathrm{~mm}$ external tetraethylammonium (TEA), which inhibits a variety of potassium channels, including Kv1.1, Kv1.6, KCNQ, Kv3, and BK channels (Coetzee et al., 1999). TEA had little effect on the low-threshold component of ramp current (reduction by $9 \pm 5 \%$ for current measured at $-50 \mathrm{mV}$ evoked by $60 \mathrm{mV} / \mathrm{s}$ ramp; $n=6$ ) but dramatically reduced the higher-threshold component of outward current (reduction by $72 \pm 19 \%$ of current measured at $-28 \mathrm{mV} ; n=8$ ) (Fig. 5C).

The most obvious remaining possibility is that the lowthreshold component of outward current represents A-type potassium current, which is prominent in VTA neurons (Koyama and Appel, 2006b) and can activate and inactivate over subthreshold voltages. Somatodendritic $I_{\mathrm{A}}$ in neurons is sensitive to 
4-AP, with a typical half-blocking concentration of $\sim 1 \mathrm{mM}$ (reviewed by Song, 2002; Jerng et al., 2004), and 4-AP is often used at millimolar concentrations to study functional roles of $I_{\mathrm{A}}$ in current-clamp experiments. We tested the effect of $10 \mathrm{~mm}$ 4-AP on step and ramp currents (Fig. 6). As expected from previous experiments testing 4-AP on $I_{\mathrm{A}}$ in VTA neurons (Koyama and Appel, 2006b), we found that $10 \mathrm{~mm}$ 4-AP effectively inhibited transient current elicited by step depolarizations (Fig. 6A). Peak current elicited by steps from -88 or -98 to $-58 \mathrm{mV}$ was inhibited by an average of $89 \pm 4 \%(n=$ 4 ), consistent with a half-blocking concentration of 4-AP near $1 \mathrm{~mm}$. In addition to inhibiting peak $I_{\mathrm{A}}$, however, 4-AP appeared to slow its decay, so that current in $10 \mathrm{~mm}$ 4-AP was actually slightly larger than control after $\sim 300 \mathrm{~ms}$. Similar "cross-over" of currents before and after 4-AP has been evident in previous experiments on cardiac and neuronal $I_{\mathrm{A}}$ (Thompson, 1982; Castle and Slawsky, 1993; Jackson and Bean, 2007), including in VTA neurons (Koyama and Appel, 2006b).

When studied with ramp-evoked currents, the most obvious effect of 4-AP was a dramatic enhancement of overall outward currents. Figure $6 B$ shows an example of application of $10 \mathrm{~mm} 4-\mathrm{AP}$ with a 50 $\mathrm{mV} / \mathrm{s}$ ramp. In the presence of $10 \mathrm{~mm}$ 4-AP, the ramp-evoked current from -70 to $-55 \mathrm{mV}$ was inhibited, but there was a dramatic increase in the outward current evoked at voltages positive to $-55 \mathrm{mV}$. Using ramps of $50 \mathrm{mV} / \mathrm{s}$, there was on average a reduction of outward current at $-58 \mathrm{mV}$ by $81 \pm 26 \%(n=4)$ and an enhancement of outward current at $-43 \mathrm{mV}$ by $262 \pm 284 \%(n=6)$. With a ramp speed of $20 \mathrm{mV} / \mathrm{s}$ (Fig. 6C), there was less low-threshold outward current in control, and there was a less pronounced inhibitory effect of 4-AP on this current (although the inhibition was still present). However, there was a dramatic enhancement of the outward current positive to $-60 \mathrm{mV}$, even more dramatic than with $50 \mathrm{mV} / \mathrm{s}$ ramps because the control current is so small with $20 \mathrm{mV} / \mathrm{s}$ ramps.

These effects of 4-AP are similar to those previously seen in acutely dissociated tuberomammillary nucleus neurons (Jackson and Bean, 2007), where they were interpreted as reflecting a statedependent interaction of 4-AP with the channels underlying $I_{\mathrm{A}}$, such that 4-AP binds tightly to closed channels but must unbind before channels can inactivate. According to this interpretation, the unbinding of toxin can produce a dramatic enhancement of current for some voltage protocols, especially slow depolarizations evoked by ramps.

The effectiveness of 4-AP in blocking the initial portion of the low-threshold ramp-evoked current is consistent with this current originating from $I_{\mathrm{A}}$. However, the dramatic enhancement of the later portion of the low-threshold current obviously makes it impossible to isolate $I_{\mathrm{A}}$ by subtraction of traces before and after
4-AP. The mixed inhibition and enhancement also makes it virtually impossible to interpret the effects of 4-AP in current clamp. In fact, we found that 4-AP generally slows rather than speeds the spontaneous firing of VTA neurons (data not shown), suggesting that it produces a net enhancement of $I_{\mathrm{A}}$ during the interspike depolarization. Slowing of pacemaking by 4-AP was also seen previously in acutely dissociated histaminergic neurons of the tuberomammillary nucleus (Jackson and Bean, 2007). Thus, although 4-AP is generally considered to be an inhibitor of $I_{\mathrm{A}}$, it may often have a net enhancing effect under physiological conditions, at least during pacemaking.

As a possible alternative to 4-AP as a blocker of $I_{\mathrm{A}}$, we tested the effect of low concentrations of external $\mathrm{Ba}^{2+}$, which has been shown recently to block $I_{\mathrm{A}}$ in CA1 pyramidal neurons (Losonczy and Magee, 2006; Gasparini et al., 2007). Application of $0.5 \mathrm{~mm}$ $\mathrm{Ba}^{2+}$ reduced the peak of step-evoked transient $I_{\mathrm{A}}$ (Fig. $7 A$ ) by an average of $69 \pm 11 \%(n=10) . \mathrm{Ba}^{2+}$ inhibited the subthreshold ramp-evoked current with similar potency, reducing the lowthreshold component of current elicited by a $60 \mathrm{mV} / \mathrm{s}$ ramp (Fig. $7 B$ ) by an average of $61 \pm 10 \%$ (measured at $-50 \mathrm{mV} ; n=12$ ). The nearly identical potency of $\mathrm{Ba}^{2+}$ on step-evoked and rampevoked current supports the idea that the ramp-evoked current is carried by the same $I_{\mathrm{A}}$ channels carrying the inactivating step- 

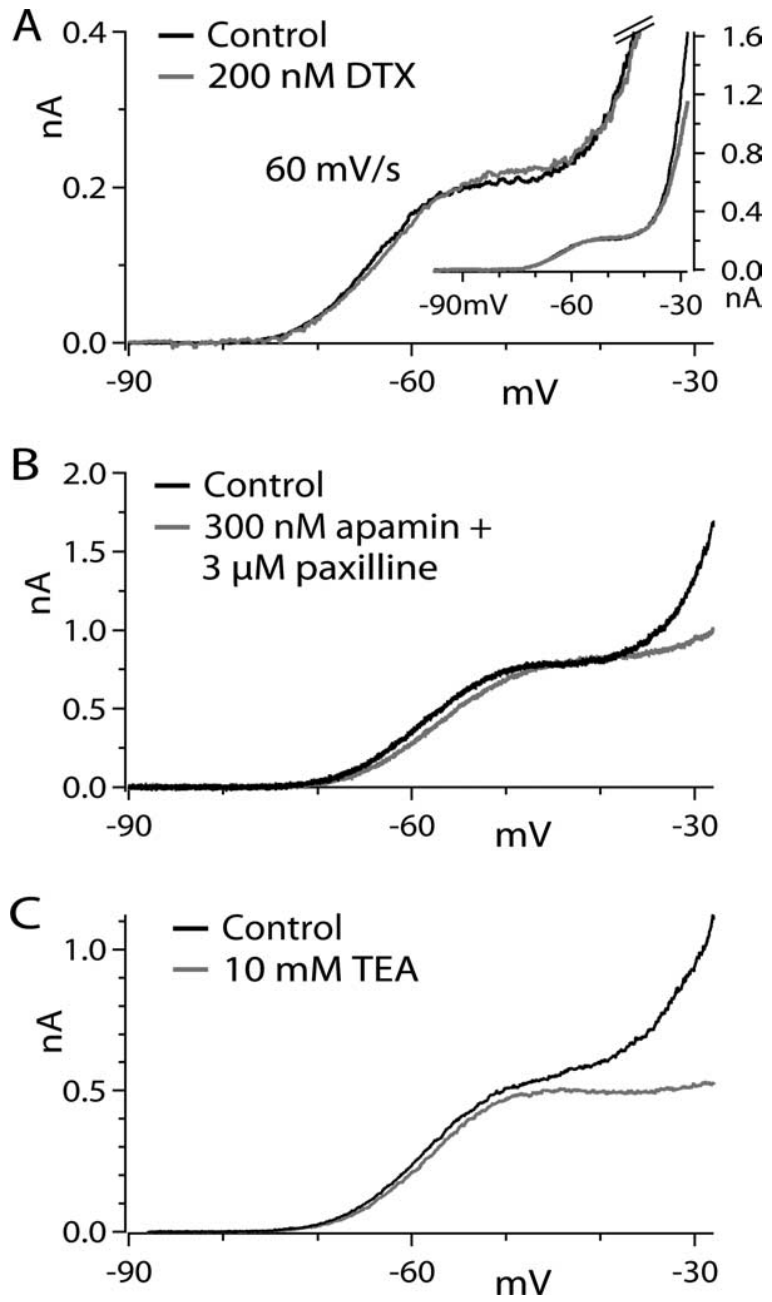

Figure 5. Pharmacology of ramp-evoked currents. $A$, Currents evoked by a $60 \mathrm{mV} / \mathrm{s}$ ramp from -98 to $-28 \mathrm{mV}$ before and after application of $200 \mathrm{~nm} \alpha$-dendrotoxin. Currents were recorded in $2 \mathrm{~mm} \mathrm{CsCl}$ and $300 \mathrm{~nm}$ TTX. Currents are truncated at $400 \mathrm{pA}$ to show low-threshold components more clearly. Inset, Currents shown at full scale to illustrate $\sim 25 \%$ inhibition of high-threshold component of the current. $\boldsymbol{B}$, Currents evoked by a $60 \mathrm{mV} / \mathrm{s}$ ramp before and after application of $300 \mathrm{~nm}$ apamin plus $3 \mu \mathrm{m}$ paxilline. Currents were recorded in $2 \mathrm{~mm} \mathrm{CsCl}$ and $300 \mathrm{~nm}$ TTX. C, Currents evoked by a $60 \mathrm{mV} / \mathrm{s}$ ramp before and after application of $10 \mathrm{~mm}$ TEA. For all traces, linear leak current was subtracted, using a linear fit to current between -88 and $-75 \mathrm{mV}$ to define leak.

evoked current. Unlike $4-\mathrm{AP}, \mathrm{Ba}^{2+}$ reduced both step-evoked and ramp-evoked currents without changing their time dependence or voltage dependence. The lack of voltage dependence is consistent with $\mathrm{Ba}^{2+}$ inhibition of $I_{\mathrm{A}}$ in cardiac muscle cells (Shi et al., 2000).

If the concavity in the plots of $-C d V / d t$ versus voltage during the interspike interval results from activation of $I_{\mathrm{A}}$, it should be reduced by application of $0.5 \mathrm{mM} \mathrm{Ba}^{2+}$. We therefore tested the effect of $\mathrm{Ba}^{2+}$ on the interspike current, as measured by $-\mathrm{CdV} / \mathrm{dt}$ from a period of spontaneous firing. In the presence of $0.5 \mathrm{mM}$ $\mathrm{Ba}^{2+}$, the rate of pacemaking increased dramatically (Fig. 7C), to an average of $355 \pm 107 \%$ of control $(1.02 \pm 0.47 \mathrm{~Hz}$ in control, $3.33 \pm 0.78 \mathrm{~Hz}$ in $\left.0.5 \mathrm{mM} \mathrm{Ba}^{2+} ; n=8\right)$. The increase in firing frequency produced by $\mathrm{Ba}^{2+}$ was accompanied by a striking change in the net ionic current calculated from $-C d V / d t$ during the interspike interval (Fig. $7 D, E$ ). The inward current flowing immediately after a spike was similar in control and in the presence of $\mathrm{Ba}^{2+}(\sim 3 \mathrm{pA}$ for the cell in Fig. $7 C-E)$. However, in
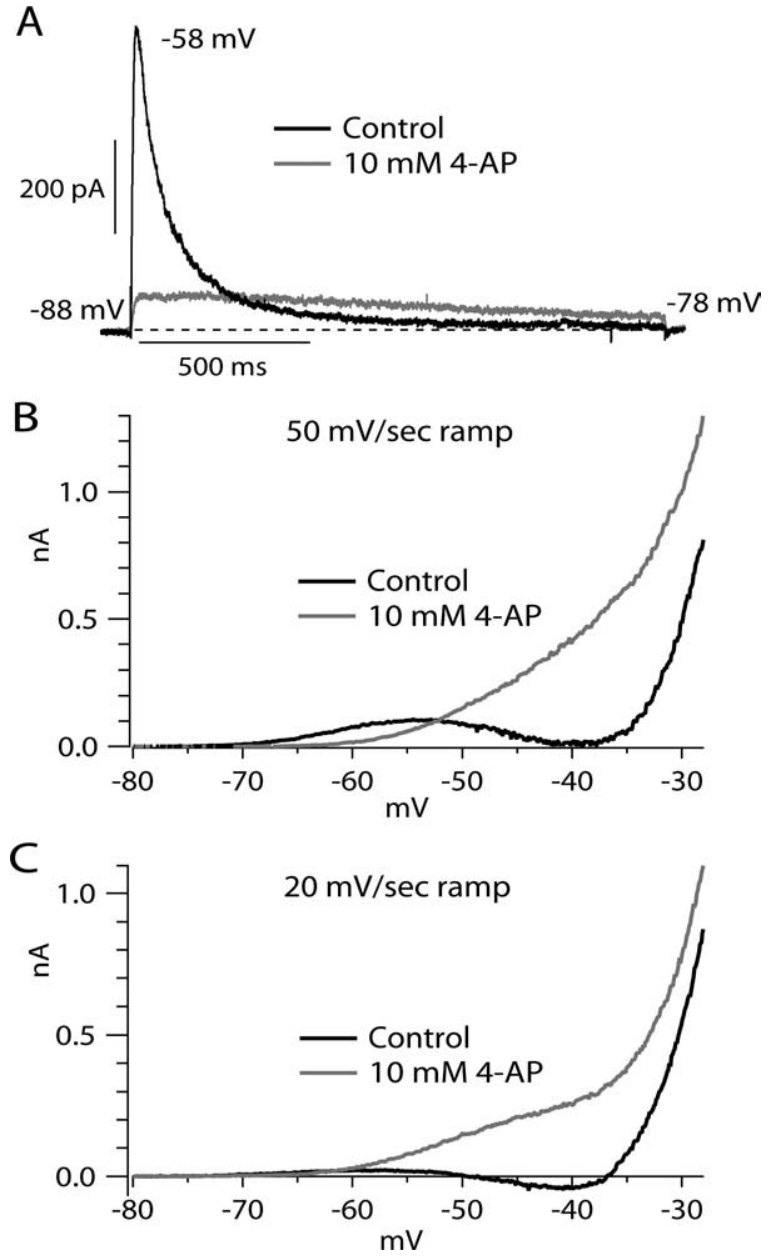

Figure 6. Effect of 4-AP on step- and ramp-evoked outward currents. $A$, Current evoked by voltage step from -88 to $-58 \mathrm{mV}$ before (black) and after (gray) application of $10 \mathrm{~mm} 4-\mathrm{AP}$. The dashed line indicates zero current. $\boldsymbol{B}$, Current evoked by a $50 \mathrm{mV} / \mathrm{s}$ ramp before (black) and after (gray) application of $10 \mathrm{~mm}$ 4-AP. C, Same for currents evoked by $20 \mathrm{mV} / \mathrm{s} \mathrm{ramp} \mathrm{(same} \mathrm{cell).}$ For traces in $\boldsymbol{B}$ and $\boldsymbol{C}$, linear leak current was subtracted.

control the inward current then decreased to a minimum of 0.7 $\mathrm{pA}$, corresponding to a long period for depolarization between -60 and $-55 \mathrm{mV}$, whereas with $\mathrm{Ba}^{2+}$, the inward current decreased only a little during the interspike current, to a minimum of $\sim 2.5 \mathrm{pA}$, so that depolarization to threshold was much more rapid. These changes could be seen clearly when net ionic current was plotted as a function of voltage (Fig. $7 E$ ); the typical concavity was greatly reduced. In collected results, the minimum inward current during the interspike interval increased by an average of $742 \pm 460 \%$, from $0.66 \pm 0.59 \mathrm{pA}$ in control to $3.25 \pm 2.68 \mathrm{pA}$ in $0.5 \mathrm{mM} \mathrm{Ba}^{2+}(n=8 ; p=0.0078$, nondirectional Wilcoxon test). To quantify the degree of concavity, we calculated the ratio of the minimum inward current to the maximal inward current reached shortly after the spike (Fig. $7 E$, filled circles). This ratio increased dramatically, from $0.16 \pm 0.14$ in control to $0.64 \pm$ 0.19 after $0.5 \mathrm{mM} \mathrm{Ba}^{2+}(n=8 ; p=0.0078$, nondirectional Wilcoxon test).

The effect of $\mathrm{Ba}^{2+}$ in greatly reducing the concavity of the net interspike ionic current is consistent with the hypothesis that this concavity results from activation of $I_{\mathrm{A}}$. The loss of $I_{\mathrm{A}}$ during the interspike interval, and consequent increase in net inward current, will by itself speed the frequency of pacemaking by increasing $d V / d t$ during the interspike interval. However, the speeding of 
firing by $\mathrm{Ba}^{2+}$ cannot necessarily be attributed to effects on $I_{\mathrm{A}}$ alone, because $\mathrm{Ba}^{2+}$ is also known to reduce other potassium currents, including resting potassium conductance mediated by two-pore domain weak inwardly rectifying $\mathrm{K}^{+}$channelrelated acid-sensitive $\mathrm{K}+$ channel 1 (TASK) or TASK-like channels (Millar et al., 2000; De Jeu et al., 2002; Meuth et al., 2003). Consistent with this, we found that $0.5 \mathrm{~mm} \mathrm{Ba}^{2+}$ increased the background or "leak" resistance of the cells. The input resistance of the neurons (measured in the range from -80 to $-70 \mathrm{mV}$ where the current-voltage relationship was ohmic) increased by an average of $26 \pm 17 \%$ in the presence of $0.5 \mathrm{mM} \mathrm{Ba}^{2+}$ [from $1.2 \pm 0.4$ $\mathrm{G} \Omega$ in control to $1.5 \pm 0.5 \mathrm{G} \Omega(n=6)$ in $\left.0.5 \mathrm{mM} \mathrm{Ba}^{2+}\right]$. The effect on resting potassium conductance probably accounts, at least in part, for the effect of $\mathrm{Ba}^{2+}$ on the trough reached after a spike, which was shifted in the depolarizing direction by an average of $3.9 \pm 1.4 \mathrm{mV}(n=8)$, from $-71.8 \pm 3.1 \mathrm{mV}$ to $-67.8 \pm 3.5 \mathrm{mV}$. The effect on trough voltage might also reflect $\mathrm{Ba}^{2+}$ inhibition of potassium channels activated during the spike.

Although the overall effect of $\mathrm{Ba}^{2+}$ on firing frequency likely reflects actions on multiple types of potassium channels, reduction of $I_{\mathrm{A}}$ is likely to be a dominant element, based on the reduction of the concavity and dramatic increase of net inward ionic current during the interspike interval. For a different way of assessing the role of the subthreshold outward current mediated by $I_{\mathrm{A}}$ in regulating the rate of spontaneous firing, we took advantage of the cell-to-cell variability of firing rate to test whether there was a correlation between firing rate and the prominence of the dynamic outward current at subthreshold voltages. In these experiments, we first recorded spontaneous firing in current clamp and then did voltage-clamp experiments to explore the relationship between the voltage dependence of ramp-evoked current and the trajectory of the interspike voltage during spontaneous firing. The data in Figure 8, $A$ and $B$, shows an example. In this neuron, which fired spontaneously at $1.3 \mathrm{~Hz}$, the rate of interspike depolarization was $22 \mathrm{mV} / \mathrm{s}$ (measured in the central region of the interspike interval) (Fig. $8 A$ ). Figure $8 B$ shows the subthreshold currents elicited by ramps delivered at speeds of 5 , $10,20,30$, or $40 \mathrm{mV} / \mathrm{s}$ in this neuron, recorded in the same physiological solutions used for current-clamp recordings, with no correction for leak conductance. As expected from the previous results, there were two components of nonlinear voltagedependent current evident: an inward component corresponding to persistent sodium current, first evident positive to approximately $-50 \mathrm{mV}$, and an outward component at more negative voltages, with the outward component showing a steep dependence on ramp speed. For ramp speeds of 5 or $10 \mathrm{mV} / \mathrm{s}$, there was no obvious nonlinear outward component, and the net current was inward at all voltages. For the ramp at $20 \mathrm{mV} / \mathrm{s}$, there was a

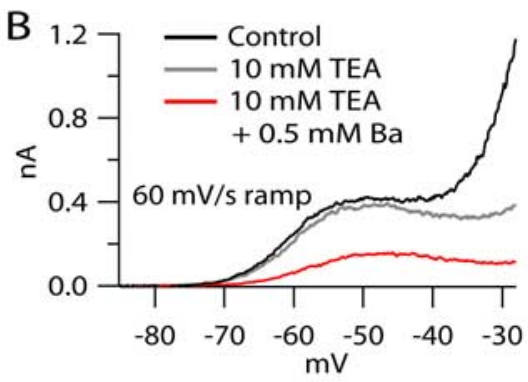

$0.5 \mathrm{mM} \mathrm{Ba} \quad 3.4 \mathrm{~Hz}$
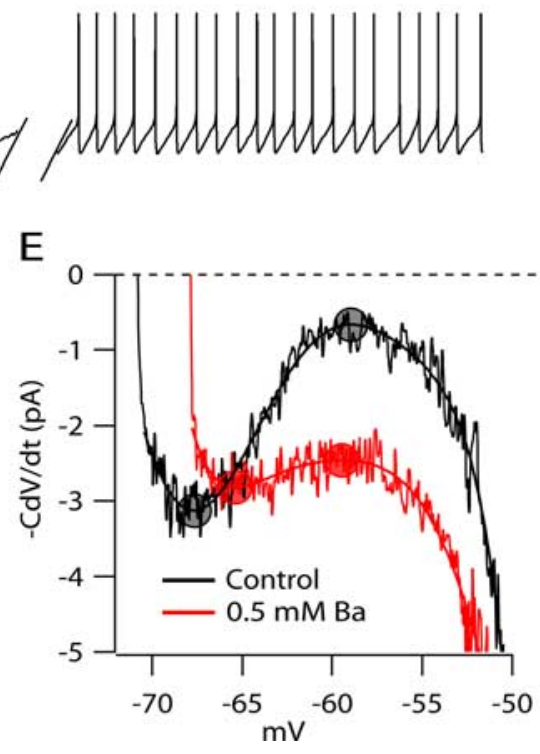

Figure 7. Effect of $0.5 \mathrm{~mm} \mathrm{Ba}^{2+}$ on step- and ramp-evoked $I_{A}$ and on net ionic current during the interspike voltage trajectory. $A$, Outward currents evoked by steps to $-48 \mathrm{mV}$ in control (black), after application of $10 \mathrm{~mm}$ TEA (gray), and in the presence of ramp. Currents were recorded in $300 \mathrm{~nm}$ TTX and were corrected for linear leak current. $C$, Effect of $0.5 \mathrm{~mm} \mathrm{Ba}{ }^{2+}$ on spontaneous firing. D, Effect of $\mathrm{Ba}^{2+}$ on net ionic current during the interspike interval, calculated from $-\mathrm{C} \times d V / d t$. Voltage trajectories were spes over 82 spikes in control and 102 spikes in the presence of $0.5 \mathrm{~mm}$ Ba. Net ionic current was calculated from $-C X$ $d V / d t$ and digitally filtered at $0.5 \mathrm{kHz}$. E, Net ionic current as a function of voltage in control and in the presence of $0.5 \mathrm{~mm} B$ Ba. To measure maxima and minima for net ionic current in the interspike interval, the experimental record of $-C \times d V / d t$ in each condition was fit by a seventh-order polynomial, and the maxima and minima (filled circles) were determined from the fitted curve.

small outward current, so that the total current was just below zero, approaching zero most closely near $-60 \mathrm{mV}$. For the ramp at $30 \mathrm{mV} / \mathrm{s}$, the outward current component was much larger, so that the net current was outward from -62 to $-50 \mathrm{mV}$.

This behavior in voltage-clamp seems well correlated with the speed of spontaneous depolarization during natural pacemaking in this neuron. Interpolating between the behavior during ramps delivered at 20 and $30 \mathrm{mV} / \mathrm{s}$, it appears that the net ramp-evoked current would first cross zero to become outward with a ramp speed near $\sim 25 \mathrm{mV} / \mathrm{s}$ (Fig. $8 \mathrm{C}$, green symbols), very close to the rate of natural spontaneous depolarization during the interspike interval. The different current-voltage relationships at different ramp speeds give a rationale for the natural interspike depolarization rate in this cell: it is the speed at which net ionic current barely remains net inward. Also, it is clear from the records that the differences in the current-voltage relationships for different ramp speeds is due almost entirely to the highly nonlinear behavior of the dynamic outward component of current from $I_{\mathrm{A}}$, rather than changes in any other component of subthreshold current.

Figure $8 C$ shows the maximum (i.e., most positive) current achieved as a function of ramp speed for three individual neu- 

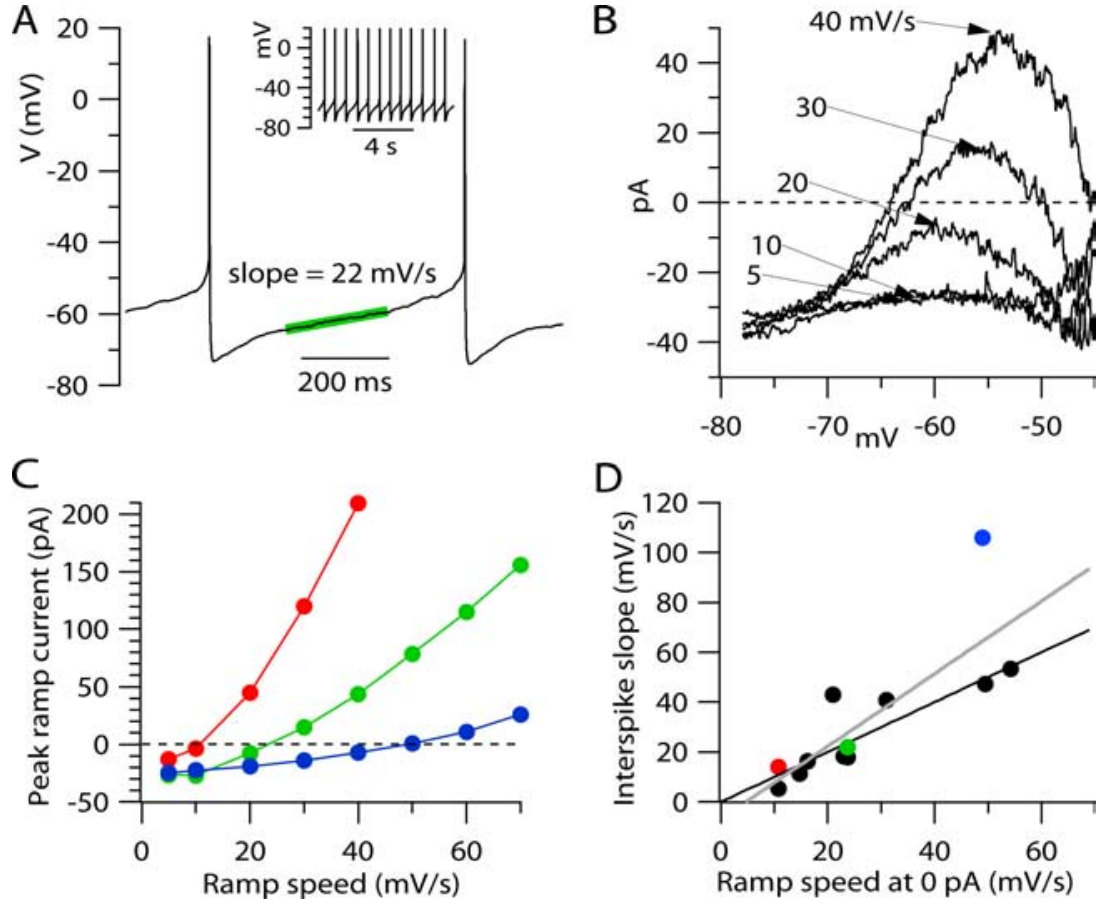

Figure 8. Comparison between interspike depolarization during spontaneous firing and ramp-evoked currents in individual neurons. $\boldsymbol{A}$, Interspike interval between two action potentials during spontaneous firing of VTA neuron. Green line, Linear fit to voltage trajectory during interspike interval in central region (30-70\% of interval between spike peaks). Inset, Longer period of pacemaking in same neuron. $\boldsymbol{B}$, Total membrane current evoked by ramps from $-78 \mathrm{mV}$ to $-45 \mathrm{mV}$ delivered at $5,10,20,30$, or $40 \mathrm{mV} / \mathrm{s}$ in same cell as in $\boldsymbol{A}$, studied in voltage clamp. There was no correction for leak current. Current during the ramp is plotted as a function of ramp voltage (averaged in bins of $0.1 \mathrm{mV}$ ). C, Maximum (most positive) ramp current during ramps plotted against ramp speed. Each color indicates data from an individual cell (green corresponds to cell whose data are shown in $\boldsymbol{A}$ and $\boldsymbol{B}$ ). $\boldsymbol{D}$, Slope of interspike depolarization during current clamp (determined as in $\boldsymbol{A}$ ) plotted against interpolated ramp speed at which current crosses 0 pA to become outward, determined from data as in C, for 12 individual neurons. Solid line, Slope of unity; gray line, linear fit (slope $=1.45$; intercept $=-6.73$; linear correlation coefficient $=0.88 ; p=0.003$, Spearman rank correlation). Colored symbols correspond to cells shown in $C$.

rons. In each case, the net membrane current was below zero (inward) for ramp speeds of 5 and $10 \mathrm{mV} / \mathrm{s}$, and increased steeply with more rapid ramp speeds. The steepness of the increase, and the magnitude of the outward currents, varied from cell to cell, so that the ramp speed at which net current crossed zero to become outward varied from $\sim 11$ to $\sim 50 \mathrm{mVs}$ among these three neurons. Figure $8 \mathrm{D}$ plots for 12 neurons the rate of interspike depolarization during spontaneous firing, measured in current clamp as in Figures $1 D$ and $8 A$, as a function of the ramp speed at which net membrane current just became outward, determined from the zero-current intercept of voltage-clamp experiments as in Figure $8 C$. Although both values vary considerably from cell to cell, they showed a high degree of correlation. The most critical factor determining the ramp speed at which net current became outward was the steep dependence of the subthreshold outward component of current on ramp speed. Thus, this component of current appears to play an especially critical role in regulating the speed of interspike depolarization.

In our analysis, the calculation of ionic current from $-C \times$ $d V / d t$ is precise in the case that the relevant areas of membrane are isopotential, so that changes in voltage (recorded at the cell body) reflect solely membrane ionic current rather than any axial current flow between adjacent compartments of the neuron. This may be a reasonable approximation for the slow changes in voltage during the interspike interval. In a study on dopaminergic neurons in the substantia nigra, Häusser et al. (1995) found that there is good isopotentiality over the dendritic tree for small volt- age changes produced by current injection into the cell body, with $<20 \%$ attenuation of the voltage change as far as $200 \mu \mathrm{m}$ from the cell body, farther than the typical location of the initial segment of the axon (usually coming off a dendritic branch), where spike initiation occurs. Assuming that VTA neurons are not dramatically different, this suggests that the assumption of isopotentiality during the slow voltage changes of the interspike interval may be reasonable. Nevertheless, to more rigorously address this issue, we performed a series of experiments using acutely dissociated VTA neurons, in which isopotentiality is more certain.

We enzymatically dissociated neurons from the VTA region of P15-P18 mice and identified dopaminergic neurons by expression of EGFP. The isolated dopaminergic VTA neurons were almost always spontaneously active (Fig. 9A). The average firing rate was $4.9 \pm 2.7 \mathrm{~Hz}\left(34^{\circ} \mathrm{C} ; n=\right.$ $9)$, faster than the average rate we measured in brain slice $(2.1 \pm 1.1 \mathrm{~Hz})$. The faster firing of dissociated neurons might reflect loss of the dendritic tree if this acts as a net capacitative load. Average cell capacitance of dissociated neurons was $13 \pm$ $6 \mathrm{pF}(n=14)$, compared with $54 \pm 21 \mathrm{pF}$ $(n=45)$ for cells in brain slice. Action potentials had a width at half-maximum amplitude of $1.4 \pm 0.5 \mathrm{~ms}(n=9)$, essentially identical to the brain slice recordings $(1.4 \pm 0.3 \mathrm{~ms})$. As reported previously for VTA neurons isolated from rats (Koyama et al., 2005), the regularity of firing varied considerably from cell to cell, with an average coefficient of variation for interspike intervals of $26 \pm 11 \%$ (mean $\pm \mathrm{SD} ; n=9$ cells).

The voltage range over which pacemaking occurred was very similar in dissociated neurons (average trough voltage, $-68.2 \pm$ $4.9 \mathrm{mV}$; average spike threshold, $-37.9 \pm 4.2 \mathrm{mV} ; n=9$ ) as in slice (average trough voltage, $-67.7 \pm 5.2 \mathrm{mV}$; average spike threshold, $-41.1 \pm 3.9 \mathrm{mV} ; n=50$ ). Figure $9 B$ shows the net ionic current calculated from $-C \times d V / d t$ and plotted as a function of voltage for the cell whose spontaneous firing is shown in Figure $9 A$. The shape of net ionic current as a function of voltage during the interspike interval was essentially identical in isolated neurons as in slice recordings, with a distinct concavity such that inward current reached a minimum between -60 and $-55 \mathrm{mV}$. On average, the smallest inward current occurred at $-55 \pm 5 \mathrm{mV}$ $(n=9)$. The minimum in net inward current varied from 0.2 to $2.2 \mathrm{pA}$ in individual cells, with an average of $1.0 \pm 0.6 \mathrm{pA}(n=9)$. The degree of concavity, calculated as the ratio of the minimum inward current to the maximal inward current reached shortly after the spike, was $0.19 \pm 0.17(n=9)$, very similar to the results from slice $(0.16 \pm 0.14 ; n=8)$.

Voltage-clamp recordings of subthreshold $I_{\mathrm{A}}$ in dissociated neurons were also very similar to those in brain slice. Figure $9 C$ shows ramp-evoked currents in a dissociated VTA neuron evoked by a series of ramps with speeds from 5 to $70 \mathrm{mV} / \mathrm{s}$, recorded at $34^{\circ} \mathrm{C}$ (and in the presence of $300 \mathrm{~nm}$ TTX and $10 \mathrm{~mm}$ TEA to better define the component of subthreshold outward 
current). Ramps at 5 and $10 \mathrm{mV} / \mathrm{s}$ did not evoke clear nonlinear outward current, whereas ramps of $20 \mathrm{mV} / \mathrm{s}$ or faster evoked a substantial component of outward current in the range between -70 and -50 $\mathrm{mV}$, with increasing amounts of current with faster ramps. The voltage dependence of low-threshold outward current was very similar as in slice recordings. For current evoked by ramps of $60 \mathrm{mV} / \mathrm{s}$, current began to activate near $-70 \mathrm{mV}$ and (in the presence of TEA to block the higherthreshold current) reached a peak near $-50 \mathrm{mV}$ (Fig. 9C), essentially identical to the voltage dependence determined in slice recordings under the same conditions (Figs. 5C, 7B). When current was plotted as a function of ramp speed (Fig. 9D), the relationship for dissociated cells was highly nonlinear, with an average exponent of $2.5 \pm 0.8(n=5)$, similar to slice recordings $(2.6 \pm 0.8)$. Thus, the behavior of the low-threshold outward current in dissociated VTA dopaminergic neurons was indistinguishable from that recorded in slice.

To our surprise, the magnitude of ramp-evoked subthreshold $I_{\mathrm{A}}$ was not dramatically less in dissociated cells than in intact cells in brain slice. The average magnitude of current evoked by a $60 \mathrm{mV} / \mathrm{s}$ ramp was $55 \pm 35 \mathrm{pA}(n=5$, measured at $-50 \mathrm{mV}$ in the presence of $300 \mathrm{~nm}$ TTX and $10 \mathrm{~mm}$ TEA) in dissociated neurons, compared with $64 \pm 42 \mathrm{pA}(n=6)$ in brain slice recordings under the same conditions. When normalized to cell capacitance, the current density in dissociated cells was $5.6 \pm 1.9 \mathrm{pA} / \mathrm{pF}(n=5)$, substantially higher than in brain slice $(2.2 \pm 1.8$ $\mathrm{pA} / \mathrm{pF} ; n=6 ; p=0.023$, nondirectional Mann-Whitney test). The comparison suggests that $I_{\mathrm{A}}$ is expressed at higher density in the cell body than in the dendrites. This is consistent with the observations of Gentet and Williams (2007) in substantia nigra dopaminergic neurons, but opposite to CA1 hippocampal pyramidal neurons, where the density of $I_{\mathrm{A}}$ is higher in dendrites (Hoffman et al., 1997).

\section{Discussion}

Our results show that $I_{\mathrm{A}}$ flows at subthreshold voltages during voltage trajectories similar to normal pacemaking in VTA neurons and suggest that subthreshold $I_{\mathrm{A}}$ is an especially effective element for controlling pacemaking frequency because of its striking dependence on the rate of depolarization. $I_{\mathrm{A}}$ at subthreshold voltages is near zero in the steady state and, thus, does not interfere with depolarization to threshold for very slow rates of depolarization (e.g., $5 \mathrm{mV} / \mathrm{s}$ ). However, the magnitude of subthreshold $I_{\mathrm{A}}$ increases very steeply with increasingly rapid rates of depolarization, especially in the range from 10 to $40 \mathrm{mV} / \mathrm{s}$, rates typical of natural pacemaking. This steep increase provides a powerful negative feedback element to promote slow firing.

The analysis using current-clamp records shows that
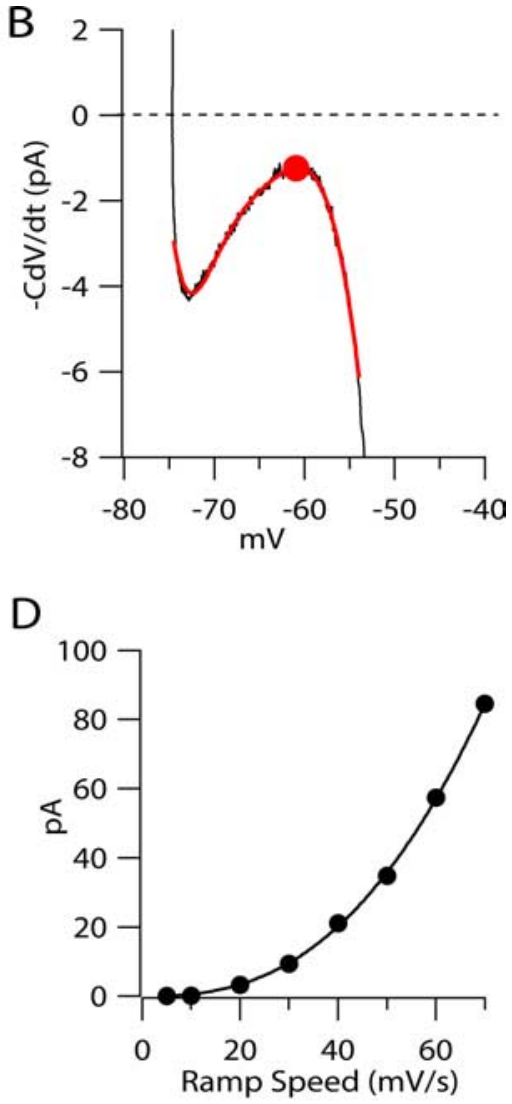

Figure 9. Nonmonotonic voltage dependence of net ionic current and subthreshold outward current in acutely dissociated VTA V/s, measured in the presence of $300 \mathrm{~nm}$ TTX and 10 mu TEA $\left(34^{\circ} \mathrm{C}\right)$. 0 correction for leak current. $D$, Peak ramp-evoked after correcting for linear leak as in Figure 3. Solid line, Fit to power function, $f(x)=a x^{b}+c$ with $a=0.0016, b=2.6$, and $c=$ 0 . Power function was fitted between 5 and $40 \mathrm{mV} / \mathrm{s}$ and extrapolated to higher values.

signal-averaging of voltage trajectories can be used to derive measurements of net ionic current at the sub-pA level. This technique should be generally useful for analyzing currents influencing pacemaking in a variety of neurons. By itself, the time and voltage dependence of net ionic current calculated from $-C \times d V / d t$ can only be suggestive of what current components are present. For example, the concavity of the current-voltage relationship in VTA neurons, with much smaller inward current between -60 and $-55 \mathrm{mV}$ than between -70 and $-65 \mathrm{mV}$, could in principle result from voltage-dependent deactivation of an inward current such as $I_{\mathrm{h}}$, rather than voltage-dependent activation of an outward current. However, complementary voltage-clamp experiments, which allow experimental variation of time and voltage dependence as well as pharmacological experiments more easily interpreted than in current clamp, can help identify components from specific channel types. In our experiments, the voltage-clamp results strongly suggest that the behavior of $-C \times d V / d t$ in current clamp represents dynamic activation of $I_{\mathrm{A}}$, because the voltage-clamp experiments show that $I_{\mathrm{A}}$ is activated in exactly this voltage range, with no other active current components evident. It would be interesting to carry out a similar analysis in cells in which $I_{\mathrm{h}}$ plays a major role in 
pacemaking, such as thalamic relay neurons (McCormick and Pape, 1990) or a subset of dopaminergic neurons in the substantia nigra (Seutin et al., 2001; Neuhoff et al., 2002).

During natural firing, net inward ionic current typically reaches a local maximum of 3-5 pA near $-65 \mathrm{mV}$, immediately after the spike. This is smaller than steady-state inward current near $-65 \mathrm{mV}$, as determined by slow ramps, which is typically $10-30$ pA (Figs. $3 B, 8 B, C, 9 C$ ). The difference likely reflects postspike potassium currents that are active during on-going spiking but not present during ramps (which start from a steady holding potential of $-78 \mathrm{mV}$ ). Most likely, multiple voltage-dependent and calcium-activated potassium conductances are activated during spikes and then decay after the spike over tens of milliseconds. Some spike-activated conductances may decay slowly enough during the interspike interval to overlap with activation of $I_{\mathrm{A}}$, and the decay of some (for example SK calcium-activated potassium current) might even be incomplete over the entire interspike interval. Such spike-evoked potassium currents will influence the net inward current during the interspike interval and thus influence pacemaking frequency. However, in all cases, their influence would be expected to decrease with time during the interspike interval, in contrast to the activation of $I_{\mathrm{A}}$.

Other potassium currents able to be activated at subthreshold voltages, such as Kv1-mediated currents or M currents (known to be present in VTA neurons) (Koyama and Appel, 2006a), could be progressively activated during the interspike interval. These have relatively slow kinetics of activation and their activation would be minimal for fast rates of interspike depolarization and maximal for slow rates. This is opposite to the behavior of $I_{\mathrm{A}}$ and to the predominant component of subthreshold outward current in voltage clamp, and such currents would not have the feedback property of increasing with rate of depolarization. However, such currents might be activated and contribute to slowing interspike depolarization in cells in which depolarization is slowest, where interspike $I_{\mathrm{A}}$ is smallest. Blocking $\mathrm{M}$ current has inconsistent effects on pacemaking of VTA neurons, speeding firing in dissociated neurons but having no effect in brain slice (Koyama et al., 2007).

In previous recordings of $I_{\mathrm{A}}$ from neurons in the tuberomammillary nucleus, there was no detectable subthreshold outward current elicited by ramps at $20 \mathrm{mV} / \mathrm{s}$ (Jackson and Bean, 2007), but in VTA neurons this depolarization rate elicits a sizeable dynamic current attributable to $I_{\mathrm{A}}$. Typical rates of interspike depolarization during natural pacemaking were faster in tuberomammillary neurons ( $65 \pm 4 \mathrm{mV} / \mathrm{s})$ (Jackson and Bean, 2007) compared with VTA neurons $(29 \pm 22 \mathrm{mV} / \mathrm{s})$. Thus, it is plausible that the kinetic properties of $I_{\mathrm{A}}$ in different neurons are "tuned" to be appropriate for regulating different firing rates. Somatodendritic A-type channels are believed to be complexes of $\mathrm{Kv} 4$ pore-forming subunits with two types of accessory proteins, Kv-channel-interacting proteins and dipeptidyl-peptidase-like proteins (for review, see Jerng et al., 2004). The accessory subunits occur in multiple forms and can strongly influence gating kinetics, perhaps underlying such cell-specific tuning (An et al., 2000; Beck et al., 2002; Zagha et al., 2005; Barghaan et al., 2008). It would be interesting to relate the kinetic behavior of native currents in VTA neurons to specific channel subunits, as done recently for A-type channels in cerebellar granule neurons (Amarillo et al., 2008).

$I_{\mathrm{A}}$ is similar to voltage-dependent sodium current in that both are inactivating voltage-dependent currents that can produce small currents at subthreshold voltages as well as large transient currents for larger depolarizations. However, our results show that they differ in an important way, in that there is no measurable $I_{\mathrm{A}}$ at subthreshold voltages in the steady state. In contrast, subthreshold sodium current is present as a true steady-state current, regardless of how slowly ramps are presented (Fig. 2D) (Fleidervish and Gutnick, 1996; Raman and Bean, 1997). The steady-state current for sodium channels amounts to at least $0.5 \%$ of the peak transient current (Taddese and Bean, 2002) and is often much larger (Raman et al., 1997; Maurice et al., 2001; Ptak et al., 2005). If there were an equivalent amount of steady-state $I_{\mathrm{A}}$, it would amount to 25-50 pA in a typical VTA neuron (with peak transient $I_{\mathrm{A}}$ of 10-20 nA for steps to -30 or $-20 \mathrm{mV}$ ) (data not shown). Current of this magnitude was present when elicited by ramps of $20-70 \mathrm{mV} / \mathrm{s}$ but is clearly not present in the steady state (as defined by $5 \mathrm{mV} / \mathrm{s}$ ramps). We estimate an upper limit of $\sim 2$ pA for any true steady-state $I_{\mathrm{A}}$ current below $-55 \mathrm{mV}$, based on traces like those in Figures $3 D, 4 A, 8 B$, and $9 C$.

The lack of substantial steady-state $I_{\mathrm{A}}$ is also at odds with previous computer models of $I_{\mathrm{A}}$ that have been used to assess its role in slow repetitive firing. These models have used HodgkinHuxley-like equations based on independent activation and inactivation processes (Connor and Stevens, 1971b; Gerber and Jakobsson, 1993; Rush and Rinzel, 1995; Xiao et al., 2004) and have had overlapping steady-state activation and inactivation curves, thus predicting substantial steady-state $I_{\mathrm{A}}$ "window" current. For example, the model of Connor and Stevens (1971b) for $I_{\mathrm{A}}$ predicts steady-state $I_{\mathrm{A}}$ near $-60 \mathrm{mV}$ amounting to $4 \%$ of maximally activated current. Such a current in a VTA neuron would completely prevent spontaneous firing by producing a net steady-state outward current near $-60 \mathrm{mV}$ of greater than 200 pA when added to the background inward current of $10-30 \mathrm{pA}$ at these voltages. Thus, the difference between the actual behavior of $I_{\mathrm{A}}$ in VTA neurons and that predicted by the models is highly significant functionally.

Recently, studies of gating kinetics of cloned Kv4 channels have led to Markov models with nonindependent activation and inactivation processes (Beck et al., 2002; Barghaan et al., 2008; Kaulin et al., 2008). These models resemble modern gating models of sodium channels, with inactivation allosterically coupled to activation. However, they differ from sodium channel models in having preferential closed-state inactivation, whereby inactivation is faster from pre-open closed states than from the open state (Bahring et al., 2001; Beck et al., 2002; Jackson and Bean, 2007; Barghaan et al., 2008; Kaulin et al., 2008). Preferential closedstate inactivation might result in minimal steady-state current if inactivation is sufficiently complete with subthreshold depolarizations. Our results suggest the importance of focusing on steady-state current in further modeling of $I_{\mathrm{A}}$ kinetics and in future experimental studies with particular combinations of cloned subunits.

A remarkable feature of pacemaking in VTA neurons is that the net inward current that drives spontaneous firing is on average only $\sim 1 \mathrm{pA}$ in the middle of the interspike interval, less than the single-channel current for many types of channels. Our results help explain how it is that the sum of currents through all ion channels active at subthreshold voltages can be reliably regulated to be such a small inward net current, thus producing slow pacemaking. By acting as a dynamic element that adjusts its size in a highly nonlinear manner, the subthreshold current from $I_{\mathrm{A}}$ serves as a "governor" that can regulate net ionic current to be just barely inward, thus promoting slow but reliable pacemaking. 


\section{References}

Amarillo Y, De Santiago-Castillo JA, Dougherty K, Maffie J, Kwon E, Covarrubias M, Rudy B (2008) Ternary Kv4.2 channels recapitulate voltage-dependent inactivation kinetics of A-type $\mathrm{K}+$ channels in cerebellar granule neurons. J Physiol 586:2093-2106.

An WF, Bowlby MR, Betty M, Cao J, Ling HP, Mendoza G, Hinson JW, Mattsson KI, Strassle BW, Trimmer JS, Rhodes KJ (2000) Modulation of A-type potassium channels by a family of calcium sensors. Nature 403: 553-556.

Bahring R, Boland LM, Varghese A, Gebauer M, Pongs O (2001) Kinetic analysis of open- and closed-state inactivation transitions in human Kv4.2 A-type potassium channels. J Physiol 535:65-81.

Barghaan J, Tozakidou M, Ehmke H, Bähring R (2008) Role of N-terminal domain and accessory subunits in controlling deactivation-inactivation coupling of Kv4.2 channels. Biophys J 94:1276-1294.

Beck EJ, Bowlby M, An WF, Rhodes KJ, Covarrubias M (2002) Remodelling inactivation gating of $\mathrm{Kv} 4$ channels by KChIP1, a small-molecular-weight calcium-binding protein. J Physiol 538:691-706.

Cameron DL, Wessendorf MW, Williams JT (1997) A subset of ventral tegmental area neurons is inhibited by dopamine, 5-hydroxytryptamine and opioids. Neuroscience 77:155-166.

Castle NA, Slawsky MT (1993) Characterization of 4-aminopyridine block of the transient outward $\mathrm{K}+$ current in adult rat ventricular myocytes. J Pharmacol Exp Ther 265:1450-1459.

Coetzee WA, Amarillo Y, Chiu J, Chow A, Lau D, McCormack T, Moreno H, Nadal MS, Ozaita A, Pountney D, Saganich M, Vega-Saenz de Miera E, Rudy B (1999) Molecular diversity of K+ channels. Ann N Y Acad Sci 868:233-285.

Connor JA, Stevens CF (1971a) Voltage clamp studies of a transient outward membrane current in gastropod neural somata. J Physiol 213:21-30.

Connor JA, Stevens CF (1971b) Prediction of repetitive firing behaviour from voltage clamp data on an isolated neurone soma. J Physiol 213:31-53.

De Jeu M, Geurtsen A, Pennartz C (2002) A Ba(2+)-sensitive K(+) current contributes to the resting membrane potential of neurons in rat suprachiasmatic nucleus. J Neurophysiol 88:869-878.

Fleidervish IA, Gutnick MJ (1996) Kinetics of slow inactivation of persistent sodium current in layer $\mathrm{V}$ neurons of mouse neocortical slices. J Neurophysiol 76:2125-2130.

Ford CP, Mark GP, Williams JT (2006) Properties and opioid inhibition of mesolimbic dopamine neurons vary according to target location. J Neurosci 26:2788-2797.

Gasparini S, Losonczy A, Chen X, Johnston D, Magee JC (2007) Associative pairing enhances action potential back-propagation in radial oblique branches of CA1 pyramidal neurons. J Physiol 580: 787-800.

Gentet LJ, Williams SR (2007) Dopamine gates action potential backpropagation in midbrain dopaminergic neurons. J Neurosci 27:1892-1901.

Gerber B, Jakobsson E (1993) Functional significance of the A-current. Biol Cybern 70:109-114.

Golding NL, Jung HY, Mickus T, Spruston N (1999) Dendritic calcium spike initiation and repolarization are controlled by distinct potassium channel subtypes in CA1 pyramidal neurons. J Neurosci 19:8789-8798.

Gong S, Zheng C, Doughty ML, Losos K, Didkovsky N, Schambra UB, Nowak NJ, Joyner A, Leblanc G, Hatten ME, Heintz N (2003) A gene expression atlas of the central nervous system based on bacterial artificial chromosomes. Nature 425:917-925.

Guan D, Lee JC, Higgs MH, Spain WJ, Foehring RC (2007) Functional roles of Kv1 channels in neocortical pyramidal neurons. J Neurophysiol 97:1931-1940.

Hahn J, Tse TE, Levitan ES (2003) Long-term K+ channel-mediated dampening of dopamine neuron excitability by the antipsychotic drug haloperidol. J Neurosci 23:10859-10866.

Hahn J, Kullmann PH, Horn JP, Levitan ES (2006) D2 autoreceptors chronically enhance dopamine neuron pacemaker activity. J Neurosci 26:5240-5247.

Häusser M, Stuart G, Racca C, Sakmann B (1995) Axonal initiation and active dendritic propagation of action potentials in substantia nigra neurons. Neuron 15:637-647.

Hodgkin AL, Huxley AF, Katz B (1952) Measurement of current-voltage relations in the membrane of the giant axon of Loligo. J Physiol 116:424-448.

Hoffman DA, Magee JC, Colbert CM, Johnston D (1997) $\mathrm{K}^{+}$channel regulation of signal propagation in dentrities of hippocampal pyramidal neurons. Nature 387:869-875.

Jackson AC, Bean BP (2007) State-dependent enhancement of subthreshold A-type potassium current by 4-aminopyridine in tuberomammillary nucleus neurons. J Neurosci 27:10785-10796.

Jerng HH, Pfaffinger PJ, Covarrubias M (2004) Molecular physiology and modulation of somatodendritic A-type potassium channels. Mol Cell Neurosci 27:343-369.

Johnson SW, North RA (1992) Two types of neurone in the rat ventral tegmental area and their synaptic inputs. J Physiol 450:455-468.

Kaulin YA, De Santiago-Castillo JA, Rocha CA, Covarrubias M (2008) Mechanism of the modulation of Kv4:KChIP-1 channels by external K+. Biophys J 94:1241-1251.

Khavandgar S, Walter JT, Sageser K, Khodakhah K (2005) Kv1 channels selectively prevent dendritic hyperexcitability in rat Purkinje cells. J Physiol 569:545-557.

Kole MH, Letzkus JJ, Stuart GJ (2007) Axon initial segment Kv1 channels control axonal action potential waveform and synaptic efficacy. Neuron 55:633-647.

Korotkova TM, Sergeeva OA, Eriksson KS, Haas HL, Brown RE (2003) Excitation of ventral tegmental area dopaminergic and nondopaminergic neurons by orexins/hypocretins. J Neurosci 23:7-11.

Koyama S, Appel SB (2006a) Characterization of M-current in ventral tegmental area dopamine neurons. J Neurophysiol 96:535-543.

Koyama S, Appel SB (2006b) A-type K+ current of dopamine and GABA neurons in the ventral tegmental area. J Neurophysiol 96:544-554.

Koyama S, Kanemitsu Y, Weight FF (2005) Spontaneous activity and properties of two types of principal neurons from the ventral tegmental area of rat. J Neurophysiol 93:3282-3293.

Koyama S, Brodie MS, Appel SB (2007) Ethanol inhibition of M-current and ethanol-induced direct excitation of ventral tegmental area dopamine neurons. J Neurophysiol 97:1977-1985.

Lammel S, Hetzel A, Häckel O, Jones I, Liss B, Roeper J (2008) Unique properties of mesoprefrontal neurons within a dual mesocorticolimbic dopamine system. Neuron 57:760-773.

Liss B, Franz O, Sewing S, Bruns R, Neuhoff H, Roeper J (2001) Tuning pacemaker frequency of individual dopaminergic neurons by Kv4.3L and KChip3.1 transcription. EMBO J 20:5715-5724.

Losonczy A, Magee JC (2006) Integrative properties of radial oblique dendrites in hippocampal CA1 pyramidal neurons. Neuron 50:291-307.

Margolis EB, Lock H, Hjelmstad GO, Fields HL (2006) The ventral tegmental area revisited: is there an electrophysiological marker for dopaminergic neurons? J Physiol 577:907-924.

Maurice N, Tkatch T, Meisler M, Sprunger LK, Surmeier DJ (2001) $D_{1} / D_{5}$ dopamine receptor activation differentially modulates rapidly inactivating and persistent sodium currents in prefrontal cortex pyramidal neurons. J Neurosci 21:2268-2277.

McCormick DA, Pape HC (1990) Properties of a hyperpolarizationactivated cation current and its role in rhythmic oscillation in thalamic relay neurones. J Physiol 431:291-318.

Metz AE, Spruston N, Martina M (2007) Dendritic D-type potassium currents inhibit the spike afterdepolarization in rat hippocampal CA1 pyramidal neurons. J Physiol 581:175-187.

Meuth SG, Budde T, Kanyshkova T, Broicher T, Munsch T, Pape HC (2003) Contribution of TWIK-related acid-sensitive $\mathrm{K}+$ channel 1 (TASK1) and TASK3 channels to the control of activity modes in thalamocortical neurons. J Neurosci 23:6460-6469.

Millar JA, Barratt L, Southan AP, Page KM, Fyffe RE, Robertson B, Mathie A (2000) A functional role for the two-pore domain potassium channel TASK-1 in cerebellar granule neurons. Proc Natl Acad Sci U S A 97:3614-3618.

Neher E (1992) Correction for liquid junction potentials in patch clamp experiments. Methods Enzymol 207:123-131.

Neuhoff H, Neu A, Liss B, Roeper J (2002) I(h) channels contribute to the different functional properties of identified dopaminergic subpopulations in the midbrain. J Neurosci 22:1290-1302.

Ptak K, Zummo GG, Alheid GF, Tkatch T, Surmeier DJ, McCrimmon DR 
(2005) Sodium currents in medullary neurons isolated from the preBotzinger complex region. J Neurosci 25:5159-5170.

Raman IM, Sprunger LK, Meisler MH, Bean BP (1997) Altered subthreshold sodium currents and disrupted firing patterns in Purkinje neurons of Scn8a mutant mice. Neuron 19:881-891.

Rudy B (1988) Diversity and ubiquity of K channels. Neuroscience 25:729-749.

Rush ME, Rinzel J (1995) The potassium A-current, low firing rates and rebound excitation in Hodgkin-Huxley models. Bull Math Biol 57:899-929.

Seutin V, Massotte L, Renette MF, Dresse A (2001) Evidence for a modulatory role of Ih on the firing of a subgroup of midbrain dopamine neurons. Neuroreport 12:255-258.

Shen W, Hernandez-Lopez S, Tkatch T, Held JE, Surmeier DJ (2004) Kv1.2containing $\mathrm{K}+$ channels regulate subthreshold excitability of striatal medium spiny neurons. J Neurophysiol 91:1337-1349.

Shi H, Wang HZ, Wang Z (2000) Extracellular Ba(2+) blocks the cardiac transient outward $\mathrm{K}(+)$ current. Am J Physiol Heart Circ Physiol 278:H295-H299.
Song WJ (2002) Genes responsible for native depolarization-activated K+ currents in neurons. Neurosci Res 42:7-14.

Taddese A, Bean BP (2002) Subthreshold sodium current from rapidly inactivating sodium channels drives spontaneous firing of tuberomammillary neurons. Neuron 33:587-600.

Thompson S (1982) Aminopyridine block of transient potassium current. J Gen Physiol 80:1-18.

Wolfart J, Neuhoff H, Franz O, Roeper J (2001) Differential expression of the small-conductance, calcium-activated potassium channel SK3 is critical for pacemaker control in dopaminergic midbrain neurons. J Neurosci 21:3443-3456.

Xiao J, Cai Y, Yen J, Steffen M, Baxter DA, Feigenspan A, Marshak D (2004) Voltage-clamp analysis and computational model of dopaminergic neurons from mouse retina. Vis Neurosci 21:835-849.

Zagha E, Ozaita A, Chang SY, Nadal MS, Lin U, Saganich MJ, McCormack T, Akinsanya KO, Qi SY, Rudy B (2005) DPP10 modulates Kv4-mediated A-type potassium channels. J Biol Chem 280:1885318861. 